OPEN ACCESS

Edited by:

David B. Collinge,

University of Copenhagen, Denmark

Reviewed by:

George Newcombe,

University of Idaho, United States

Huzefa A. Raja,

University of North Carolina at Greensboro, United States

*Correspondence: Iñigo Zabalgogeazcoa i.zabalgo@irnasa.csic.es

Specialty section: This article was submitted to

Plant Microbe Interactions, a section of the journa

Frontiers in Microbiology

Received: 17 October 2018 Accepted: 20 December 2018

Published: 16 January 2019

Citation:

Pereira E, Vázquez de Aldana $B R$, San Emeterio $L$ and Zabalgogeazcoa I

(2019) A Survey of Culturable Fungal Endophytes From Festuca rubra subsp. pruinosa, a Grass From

Marine Cliffs, Reveals a Core Microbiome. Front. Microbiol. 9:3321. doi: 10.3389/fmicb.2018.03321

\section{A Survey of Culturable Fungal Endophytes From Festuca rubra subsp. pruinosa, a Grass From Marine Cliffs, Reveals a Core Microbiome}

\author{
Eric Pereira ${ }^{1}$, Beatriz R. Vázquez de Aldana ${ }^{1}$, Leticia San Emeterio ${ }^{2}$ and \\ Iñigo Zabalgogeazcoa ${ }^{1 *}$
}

${ }^{1}$ Institute of Natural Resources and Agrobiology of Salamanca, Consejo Superior de Investigaciones Cientificas (IRNASA-CSIC), Salamanca, Spain, ${ }^{2}$ Research Institute on Innovation \& Sustainable Development in Food Chain (ISFood), Universidad Pública de Navarra, Pamplona, Spain

Festuca rubra subsp. pruinosa is a perennial grass that inhabits sea cliffs of the Atlantic coasts of Europe. In this unhospitable environment plants grow in rock crevices and are exposed to abiotic stress factors such as low nutrient availability, wind, and salinity. Festuca rubra subsp. pruinosa is a host of the fungal endophyte Epichloë festucae, which colonizes aerial organs, but its root mycobiota is unknown. The culturable endophytic mycobiota of FRP roots was surveyed in a set of 105 plants sampled at five populations in marine cliffs from the northern coast of Spain. In total, 135 different fungal taxa were identified, 17 of them occurred in more than $10 \%$ of plants and in two or more populations. Seven taxa belonging to Fusarium, Diaporthe, Helotiales, Drechslera, Slopeiomyces, and Penicillium appeared to be constituents of the core microbiome of Festuca rubra subsp. pruinosa roots because they occurred in more than $20 \%$ of the plants analyzed, and at three or more populations. Most fungal strains analyzed (71.8\%) were halotolerant. The presence of Epichloë festucae in aboveground tissue was detected in $65.7 \%$ of the plants, but its presence did not seem to significantly affect the structure of the core or other root microbiota, when compared to that of plants free of this endophyte. When plants of the grass Lolium perenne were inoculated with fungal strains obtained from Festuca rubra subsp. pruinosa roots, a Diaporthe strain significantly promoted leaf biomass production under normal and saline (200 mM NaCl) watering regimes. These results suggest that the core mycobiome of Festuca rubra subsp. pruinosa could have a role in host plant adaptation, and might be useful for the improvement of agricultural grasses.

Keywords: mycobiome, Diaporthe, Fusarium oxysporum, Epichloë, salinity, halophyte, grass

\section{INTRODUCTION}

The vegetation that inhabits coastal marine cliffs is adapted to environmental conditions that are far from optimal for plant growth and survival. The rock substrate and vertical cliffs makes soil scarce or non-existent. Sea water spray adds salinity to the scenario, and exposure to sea winds favor plant dehydration. Those conditions of low nutrient availability, salinity, and wind exposure 
can be persistent in sea cliffs, and as a result, sea cliff vegetation is often endemic, reflecting habitat specialization in order to survive under these unhospitable conditions (Doody, 2001; López-Bedoya and Pérez-Alberti, 2009).

Festuca rubra subsp. pruinosa (FRP) is a plant species common in cliffs of the Atlantic coasts of Europe (Markgraf-Dannenberg, 1980; López-Bedoya and Pérez-Alberti, 2009). This perennial grass grows as a chasmophyte in rock fissures, or in very shallow soils formed on cliff cavities and slopes. In nature this species rarely occurs away from sea cliffs, where other vegetation predominates, and its salt tolerance is greater than that of other F. rubra subspecies adapted to inland habitats (Humpreys, 1982). Some anatomical characteristics might contribute to the adaptation to cliffs of this plant, for instance, the epithet pruinosa refers to the apparent epicuticular wax coat that covers its leaves, possibly having a role in preventing water loss (Ortuñez and de la Fuente, 2010; Martínez Sagarra et al., 2017).

In addition to traits inherent to the plant genome, the plant microbiome can also contribute to adaptation. Studies of some plants adapted to high stress habitats revealed that fungal endophytes confer habitat-specific stress tolerance to their hosts, and without these fungal endophytes plant adaptation is reduced in their native habitats (Rodriguez and Redman, 2008). Examples include improved tolerance to biotic and abiotic stress factors such as disease, herbivory, heat, or salinity mediated by endophytic fungi (Clay and Schardl, 2002; Waller et al., 2005; Rodriguez et al., 2008). Some of the endophytes reported in these studies conferred improved stress tolerance to new host species, highlighting the importance that endophytic fungi could have for the improvement of agricultural crops.

Like other subspecies of Festuca rubra, FRP plants maintain associations with the fungal endophyte Epichloë festucae. This fungus systemically colonizes the stems and leaves of host plants, but not the roots, and it is transmitted vertically to seeds (Leuchtmann et al., 1994; Zabalgogeazcoa et al., 2006). Endophytic Epichloë species can have a mutualistic relationship with their hosts, and increased tolerance of symbiotic plants to biotic and abiotic stress factors have been reported to occur in some situations. For example, Epichloë festucae can produce several types of alkaloids that might protect host plants against herbivores (Clay and Schardl, 2002).

In marine cliffs the roots of FRP plants grow in rock fissures or minimal soil, forming a compact fibrous system which holds the plant and captures nutrients. The root mycobiota of FRP is unknown, and some of its components could be useful for the improvement of other plant species of agronomic interest, as it has been demonstrated in other plant-endophyte associations (Rodriguez et al., 2008). Thus, the objectives of this work were: (1) to identify the culturable endophytic mycobiota of FRP roots, (2) to determine if the presence of Epichloë affects the structure of the root mycobiota, and (3) to test if some FRP root endophytes affect the performance of another grass, Lolium perenne, when exposed to salinity.

\section{MATERIALS AND METHODS}

\section{Study Sites and Plant Sampling}

Plants of Festuca rubra subsp. pruinosa (FRP) were collected at five locations in sea cliffs in the North Atlantic coast of Spain. Three locations were in Galicia: Torre de Hércules $(\mathrm{TDH}), 43^{\circ} 23^{\prime} 09^{\prime \prime} \mathrm{N} 8^{\circ} 24^{\prime} 23^{\prime \prime} \mathrm{W}$, Cedeira (CED), $43^{\circ} 40^{\prime} 46^{\prime \prime} \mathrm{N}$ $8^{\circ} 01^{\prime} 15^{\prime \prime} \mathrm{W}$, and Estaca de Bares (EDB), $43^{\circ} 47^{\prime} 25^{\prime \prime} \mathrm{N} 7^{\circ} 41^{\prime} 16^{\prime \prime} \mathrm{W}$, and two in Asturias: San Pedro de la Rivera (SPR), $43^{\circ} 34^{\prime} 43^{\prime \prime} \mathrm{N}$ $6^{\circ} 13^{\prime} 17^{\prime \prime} \mathrm{W}$, and Cabo de Peñas (CDP), $43^{\circ} 39^{\prime} 02^{\prime \prime} \mathrm{N} 5^{\circ} 51^{\prime} 00^{\prime \prime} \mathrm{W}$. The shortest distance in straight line among these locations is $30 \mathrm{~km}$. The predominant flora in the walls of these sea cliffs mainly consisted of Festuca rubra subsp. pruinosa, Armeria spp. and Crithmum maritimum. The climate in the coast of Galicia and Asturias is mild with oceanic influence and abundant rainfall spread over the year; during the 1981-2010 period the mean annual precipitation was 1106 and $1062 \mathrm{~mm}$, and the average annual temperature 13.5 and $13.8^{\circ} \mathrm{C}$ in Galicia and Asturias, respectively (AEMET, 2012). In the spring of 2016, a total of 105 FRP plants, about 20 plants per location, were collected. Most plants grew in fissures in the rock, where soil was very scarce or absent. The plants were transported in a refrigerated cooler to the laboratory in Salamanca, and processed for the isolation of fungi from roots the day after they were sampled. Afterward the plants were transplanted to pots with a $1: 1(\mathrm{v}: \mathrm{v})$ mixture of peat and perlite and maintained in a wirehouse outdoors.

\section{Isolation of Fungi}

To isolate fungi from roots, a sample of about 20 root fragments of 4-5 cm was collected from each plant. Each root sample was surface-disinfected with a solution of $20 \%$ commercial bleach ( $1 \%$ active chlorine) containing $0.02 \%$ Tween 80 (v:v) for $6 \mathrm{~min}$, followed by treatment with an aqueous solution of $70 \%$ ethanol for $30 \mathrm{~s}$. Finally, the roots were rinsed with sterile water and cut into pieces about $5 \mathrm{~mm}$ long. Thirty root pieces of each sample were plated in two Petri plates (15 pieces/plate) with potato dextrose agar (PDA) containing $200 \mathrm{mg} / \mathrm{L}$ of chloramphenicol. This antibiotic was used to exclude the isolation of endophytic bacteria. A root sample of each of the 105 plants was prepared as outlined above, and kept in the dark at room temperature. As mycelium emerged from a root fragment into the agar, a small piece of the mycelium from the leading edge of the colony was transferred to a new PDA plate and maintained at room temperature. The root fragment and remaining mycelium were taken out of the original plate to avoid overgrowth. The plates with root samples were checked daily for the presence of fungi for about 4 weeks.

The presence of Epichloe festucae on each plant was diagnosed by isolation. Several leaf sheaths were collected from each plant, cut into fragments about $5 \mathrm{~mm}$ long, and surface disinfected by immersion in a solution of $20 \%$ commercial bleach for $10 \mathrm{~min}$. The fragments were then rinsed with sterile water, and about 15 fragments from each plant were placed in a PDA plate containing $200 \mathrm{mg} / \mathrm{L}$ of chloramphenicol. The plates were kept at room temperature, and fungi emerging from leaf fragments during the first 2-5 days were discarded together with its leaf sheath 
fragment. White Epichloë mycelium emerging from the extremes of the leaf fragments about 1 week after plating was transferred to new PDA plates for further identification.

\section{Identification of Fungi}

The fungal isolates obtained from roots were first grouped into different morphotypes according to morphological characteristics such as colony color, exudate production, mycelium appearance, and growth rate. One or a few isolates of each morphotype were used for further classification based on rDNA nucleotide sequences. Fungal DNA was extracted from a small amount of mycelium scraped from a PDA culture using the Phire Plant Direct PCR Kit (Thermo Fisher Scientific). A ribosomal DNA region including the internal transcribed spacer 1 (ITS1), 5.8S rDNA, and ITS2 was amplified by PCR using primers ITS1 and ITS4 (White et al., 1990). Amplification conditions were: $98^{\circ} \mathrm{C}$ for $5 \mathrm{~min}$, followed by 35 cycles of $98^{\circ} \mathrm{C}$ for $5 \mathrm{~s}, 54^{\circ} \mathrm{C}$ for $5 \mathrm{~s}$, and $72^{\circ} \mathrm{C}$ for $20 \mathrm{~s}$; after that the reaction was kept at $72^{\circ} \mathrm{C}$ for $1 \mathrm{~min}$. PCR amplicons were cleaned (MSB Spin PCRapace, Stratec biomedical, Germany) and sequenced at the DNA sequencing service of the University of Salamanca (Spain).

All the sequences obtained were grouped into operational taxonomic units (OTU), considering that groups of sequences with a similarity greater than $97 \%$ belonged to the same OTU. This clustering operation was done using BlastClust software (NCBI, 2004). Afterward, a sequence representative of each OTU was used to search for similar curated sequences at the UNITE fungal database. A taxonomic identity was assigned to each OTU considering that the species rank of a UNITE database match was accepted when the identity between the OTU and database sequences was greater than 97\%, and most UNITE matches corresponded to the same taxon. When the similarity was $97 \%-95 \%$, or UNITE matches corresponded to several species of the same genus, only the genus rank was accepted. In other cases the sequences were assigned to orders or families whenever it was reasonable.

\section{Analysis of Root Fungal Diversity}

For each location (referred to as population from here on), species accumulation curves showing the relationship between the number of plants sampled and the number of fungal species obtained, were estimated using the 'specaccum' function and the exact method with the Vegan Package in R (Oksanen et al., 2017). Estimations of the maximum number of fungal species at each population were obtained with the Bootstrap and Chao indexes using EstimateS 9.0 software (Colwell, 2005). Shannon's index of diversity $\left(H^{\prime}\right)$ was estimated from the relative abundance of each taxon identified. The distribution of the relative abundance of the fungal species was observed with a rank-abundance curve. The similarity of fungal communities between each pair of populations was estimated using Jaccard's index of similarity (J). It is calculated from the equation $J=c /(a+b+c)$, where ' $c$ ' is the number of fungal taxa shared between two populations, 'a' the number of fungal taxa unique to the first population and ' $b$ ' the number of fungal taxa unique to the second population (Jaccard, 1912).

\section{Effect of Epichloë on Root Mycobiota}

Species richness (number of different root endophyte species per plant) was analyzed with a two-way ANOVA with Epichloë presence $(\mathrm{E}+)$ or absence $(\mathrm{E}-)$ and plant population $(\mathrm{CED}$, CDP, EDB, SPR, and TDH) as factors. A type III sum of squares was used because the number of $\mathrm{E}+$ and $\mathrm{E}-$ plants was unbalanced.

Species accumulation curves and beta diversity index estimations, plus a Canonical Correspondence Analysis (CCA) were made using the Vegan Package in $\mathrm{R}$ (Oksanen et al., 2017). Species accumulation curves for $\mathrm{E}+$ and $\mathrm{E}-$ plants were estimated using the 'specaccum' function and the exact method. Beta-diversity indexes were estimated using the 'betadiver' function and the $\mathrm{z}$ index based on the Arrhenius species-area model (Koleff et al., 2003). Differences in beta diversity among groups were determined by Tukey multiple comparisons. A CCA was made because the gradient length of the detrended correspondence analysis (DCA) was greater than four, which indicated an unimodal response (Lepš and Šmilauer, 2003). Taxa appearing in less than three plants were omitted for this analysis; as a result, 61 taxa remained. A forward selection procedure (ordistep function) was used to determine the subset of explanatory variables (Epichloë incidence, population, Epichloë: population) explaining most variation in root mycobiome. The statistical power of the analysis was assessed by Monte Carlo permutation tests $(n=999)$.

\section{Salt Tolerance of Fungal Isolates}

A set of 46 fungal strains belonging to 20 of the most abundant genera isolated from FRP roots plus nine Epichloë festucae strains were analyzed to determine their salt tolerance in vitro. For each fungal strain a $6 \mathrm{~mm}$ diameter mycelial disk was placed in the center of $9 \mathrm{~cm}$ Petri plates with PDA containing three different concentrations of sodium chloride: $600 \mathrm{mM}$ (equivalent to sea water concentration), $300 \mathrm{mM}$, and a control without $\mathrm{NaCl}$. For each fungal strain and salt treatment three replicate plates were prepared. All plates were incubated at room temperature in the dark. The colony diameter was measured at two perpendicular axes when colonies in the fastest growing medium reached a diameter of $4-6 \mathrm{~cm}$. The effect of salinity treatments on the radial growth of fungal colonies was assessed by means of a one-way ANOVA, and statistical significance of differences among means using Tukey's test $(p<0.05)$.

\section{Extracellular Enzyme Activity}

In vitro cellulase and amylase activity was analyzed for 43 strains belonging to some of the most abundant taxa. The production of cellulase was assayed using the method described by Sunitha et al. (2013) adapted to PDA plates. For each fungal strain a $6 \mathrm{~mm}$ diameter mycelial disk was placed in the center of a $9 \mathrm{~cm}$. Petri plate and incubated for 5 days at $25^{\circ} \pm 1^{\circ} \mathrm{C}$ in the dark. After incubation the plates were flooded with $0.2 \%$ (w/v) aqueous Congo Red, and distained with $1 \mathrm{M} \mathrm{NaCl}$ for $15 \mathrm{~min}$. The presence of a clear zone surrounding the colony 
indicated cellulase activity. Amylase activity was assessed on PDA containing $2 \%(\mathrm{w} / \mathrm{v})$ soluble starch. After incubation the plates were flooded for $15 \mathrm{~min}$ with a solution of $1 \%(\mathrm{w} / \mathrm{v})$ iodine in $2 \%(\mathrm{w} / \mathrm{v})$ potassium iodide. A clear zone surrounding the colony indicated amylase activity (Hankin and Anagnostakis, 1975).

\section{Inoculation of Lolium perenne Plants With Root Endophytes From FRP}

To test whether FRP endophytes affect the growth of the grass Lolium perenne under salinity, plants were inoculated with three fungal strains belonging to some of the core taxa from FRP roots. A greenhouse experiment was conducted with a completely randomized design with 14 plant replicates for each fungal strain (Periconia S6, Penicillium E7, and Diaporthe S69) and salinity treatment (0 and $200 \mathrm{mM} \mathrm{NaCl}$ ). Seeds of Lolium perenne cv. Tivoli (DLF, Denmark) were sown in $200 \mathrm{~mL}$ plastic pots filled with a substrate composed of seven parts of peat and perlite $(1: 1)$ previously sterilized at $80^{\circ} \mathrm{C}$ for $24 \mathrm{~h}$, mixed with one part (v:v) of fungal inoculum. The fungal inoculum was a 4 week old culture of each fungus grown in autoclaved sugar beet pulp. Several seeds were sown in each pot, and thinned to four seedlings after emergence. Three weeks after germination, plants were watered with 0 or $200 \mathrm{mM} \mathrm{NaCl}$ during 3 weeks. Plants subject to the salinity treatment were watered with 50 and $100 \mathrm{mM} \mathrm{NaCl}$ on the first and third day respectively to avoid salt shock, and the $200 \mathrm{mM}$ concentration was applied from day 5 onward. After 3 weeks of salt treatment the plants were harvested.

Five replicates of each treatment (salt and fungal strain) were analyzed for $\mathrm{K}$ and $\mathrm{Na}$ concentration by inductively coupled plasma atomic emission spectroscopy (ICP-OES, Varian 720-ES). Previously, dried plant samples were calcined at $450^{\circ} \mathrm{C}$ for $8 \mathrm{~h}$, and ashes dissolved in $\mathrm{HCl}: \mathrm{HNO}_{3}: \mathrm{H}_{2} \mathrm{O}(1: 1: 8)$.

A two-way ANOVA was made to determine the effects of salt treatment and fungal strain on shoot biomass, $\mathrm{K}$ and $\mathrm{Na}$ concentrations, and differences between means were assessed using Tukey's test $(p<0.05)$. The success of the inoculation was determined after harvest by the reisolation of the inoculated fungi from surface disinfected roots, using the method above explained.

\section{RESULTS}

\section{Endophyte Isolation}

After plating 3150 root fragments on culture media, a total of 2324 fungal isolates were obtained, ranging from 355 to 578 among populations (Table 1). Most isolates emerged in the first 5 days after the placement of the roots on plates. Isolates were obtained from $73.8 \%$ of the root fragments plated. All sampled plants harbored fungi in their roots, and on average, 21 isolates were obtained from the roots of each plant.

Epichloe festucae was isolated from leaves of $65.7 \%$ of the plants. Its incidence among populations ranged from 20.0 to 100.0\% (Table 1).

\section{Identification of Fungal Isolates and Taxonomic Structure}

When the isolates of each population were grouped according to morphotypes, the TDH isolates were classified into 177 morphotypes, CED in 142, EDB in 125, SPR in 137, and those from CDP in 107.

Nucleotide sequences were obtained from one or more isolates of each morphotype. As a result, 502 ITS1-5.8S-ITS2 nucleotide sequences were obtained, and those differing in homology by less than $3 \%$ were considered to belong to the same taxon. After this clustering process, 138 different sequences remained. These sequences were used to interrogate the UNITE sequence database, and as a result 135 fungal taxa were identified (Supplementary Table S1). Twenty-three taxa were identified to a species rank, 69 to genus rank and the remaining 43 were assigned to an order, class, family or division (Table 2). All the taxa could be assigned to 64 different fungal genera, 96\% of them within the Ascomycota. Pleosporales, Hypocreales, and Eurotiales were the most representative orders, in terms of the number of taxa $(23,18$, and $10 \%$, respectively). The remaining orders were marginally represented (Figure 1). Among plant populations the number of fungal taxa ranged from 34 to 59 (Table 1).

The distribution of the taxa according to their incidence can be visualized in the rank-abundance curve shown in Figure 2. Seven species occurred in more than $20 \%$ of the plants at three

TABLE 1 | Incidence of Epichloë and fungal species richness in roots of Festuca rubra subsp. pruinosa at five populations from marine cliffs in Northern Spain.

\begin{tabular}{|c|c|c|c|c|c|c|}
\hline \multirow[t]{2}{*}{ Population } & \multirow{2}{*}{$\begin{array}{c}\text { Number of } \\
\text { plants } \\
\text { analyzed }\end{array}$} & \multirow{2}{*}{$\begin{array}{c}\text { Incidence of } \\
\text { Epichloë } \\
\text { festucae (\%) }\end{array}$} & \multicolumn{4}{|c|}{ Root mycobiota } \\
\hline & & & $\begin{array}{c}\text { Number of } \\
\text { isolates } \\
\text { obtained }\end{array}$ & Colonization $^{1}$ & $\begin{array}{c}\text { Number of } \\
\text { fungal } \\
\text { species }\end{array}$ & $\begin{array}{c}\text { Fungal } \\
\text { species per } \\
\text { plant }\end{array}$ \\
\hline $\mathrm{TDH}$ & 21 & 57.1 & 471 & 74.8 & 34 & 1.62 \\
\hline CED & 19 & 68.4 & 355 & 62.3 & 46 & 2.42 \\
\hline EDB & 22 & 77.3 & 473 & 71.7 & 47 & 2.47 \\
\hline CDP & 20 & 20.0 & 447 & 74.5 & 59 & 2.57 \\
\hline SPR & 23 & 100.0 & 578 & 83.8 & 46 & 2.19 \\
\hline Total/mean & 105 & 65.7 & 2324 & 73.8 & 135 & 1.29 \\
\hline
\end{tabular}

${ }^{1}$ Percentage of root pieces from which fungi emerged into growth medium. 
TABLE 2 | Core and abundant fungal species isolated from surface sterilized roots of Festuca rubra subsp. pruinosa at five populations from marine cliffs in northern Spain.

\begin{tabular}{|c|c|c|c|c|c|c|}
\hline Strain & Taxon & $\begin{array}{c}\text { Identity to } \\
\text { closest match } \\
(\%)\end{array}$ & $\begin{array}{c}\text { ITS sequence } \\
\text { accession } \\
\text { number }\end{array}$ & Order & $\begin{array}{l}\text { Incidence in } \\
\text { plants (\%) }\end{array}$ & $\begin{array}{c}\text { Number of } \\
\text { populations }\end{array}$ \\
\hline T150 & Fusarium oxysporum & 100 & MH578626 & Hypocreales & 57.1 & 5 \\
\hline EB4 & Diaporthe sp. A & 100 & MH578627 & Diaporthales & 54.3 & 5 \\
\hline C29 & Fusarium sp. A & 100 & MH626490 & Helotiales & 41.0 & 4 \\
\hline S75 & Helotiales sp. A & 100 & MH626491 & Helotiales & 37.1 & 5 \\
\hline T105 & Drechslera sp. & 100 & MH626492 & Pleosporales & 27.6 & 4 \\
\hline S132 & Slopeiomyces cylindrosporus & 100 & MH626493 & Magnaporthales & 27.6 & 3 \\
\hline T120 & Penicillium sp. F & 100 & MH626494 & Eurotiales & 20.0 & 5 \\
\hline S7 & Darksidea sp. & 99 & MH628220 & Pleosporales & 17.1 & 3 \\
\hline T131 & Periconia macrospinosa & 100 & MH628221 & Pleosporales & 16.2 & 3 \\
\hline T122 & Penicillium sp. A & 100 & MH628222 & Eurotiales & 14.3 & 4 \\
\hline T16 & Alternaria sp. A & 99 & MH628223 & Pleosporales & 13.3 & 3 \\
\hline S38 & Fusarium sp. B & 99 & MH628224 & Hypocreales & 13.3 & 4 \\
\hline $\mathrm{C} 2$ & Dactylonectria alcacerensis & 100 & MH628225 & Hypocreales & 13.3 & 4 \\
\hline E79 & Helotiales sp. B & 100 & MH628226 & Helotiales & 11.4 & 3 \\
\hline T140 & Alternaria sp. B & 100 & MH628227 & Pleosporales & 10.5 & 4 \\
\hline E74 & Lachnum sp. A & 99 & MH628228 & Helotiales & 10.5 & 3 \\
\hline CP17 & Trichoderma sp. B & 100 & MH628229 & Hypocreales & 10.5 & 2 \\
\hline
\end{tabular}

Only the taxa with an incidence in plants greater than 20\% are listed. Supplementary Table S1 contains the complete list of 135 taxa identified.

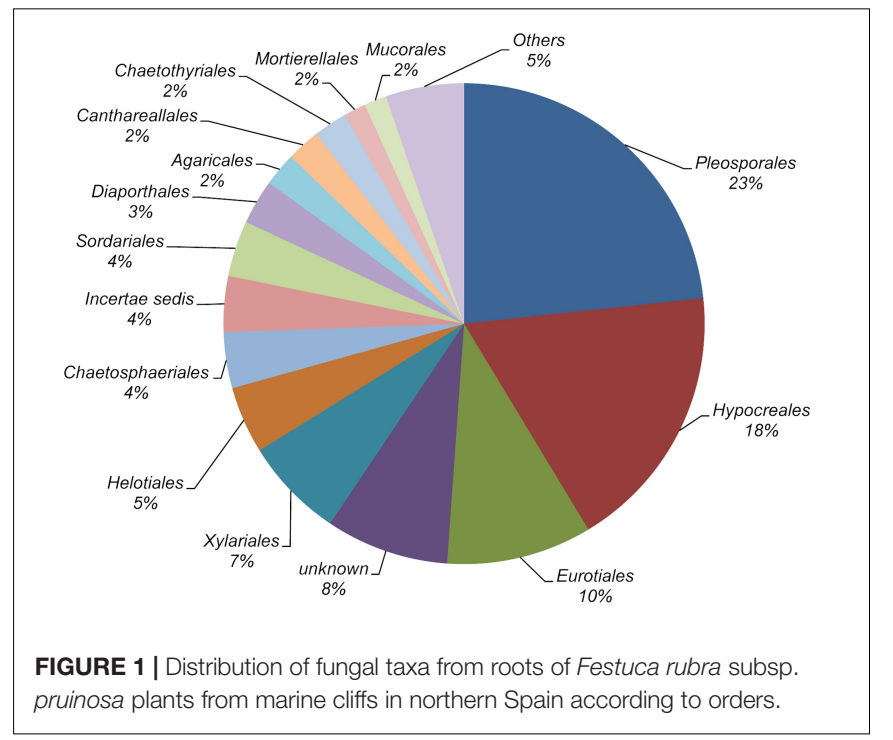

or more populations: Fusarium oxysporum (57.1\%), Diaporthe sp. A (54.3\%), Fusarium sp. A (40.9\%), Helotiales sp. A (37.1\%), Slopeiomyces cylindrosporus (27.6\%), Drechslera sp. (27.6\%), and Penicillium sp. F (20.0\%) (Table 2). The identification of several F. oxysporum strains was confirmed by Martijn Rep and Maria Constantin (University of Amsterdam) by means of an analysis of their EF1 $\alpha$ gene sequence. Because of their relatively high incidence within and among populations, these taxa could be considered as part of the core microbiome of FRP.

A second set of relatively abundant taxa were isolated from 10 to $20 \%$ of the plants, and at two or more populations (Table 2), these were Darksidea sp., Periconia macrospinosa, Penicillium sp.

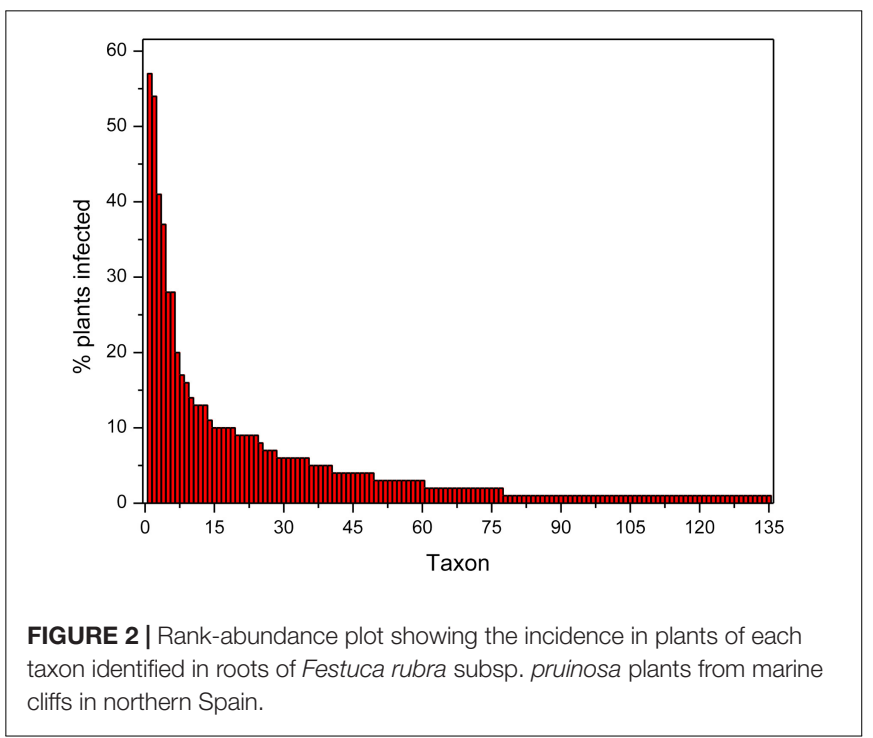

A, Alternaria sp. A, Fusarium sp. B, Dactylonectria alcacerensis, Helotiales sp. B, Alternaria sp. B, Lachnum sp. A and Trichoderma sp. B. The remaining 118 taxa were found in less than $10 \%$ of the plants and 58 of them were singletons, occurring in a single plant.

Some of most abundant taxa, like Darksidea sp., Periconia macrospinosa, Slopeiomyces cylindrosporus and Drechslera sp., belong to the group of fungi known as dark septate endophytes (DSE). Fungi from the DSE group present some particular morphological characteristics, such as septated and melanized hyphae. These characteristics were observed in hyphae from two strains of Helotiales sp. A under the light microscope. Therefore, Helotiales sp. A also seems to belong to the DSE. 
All populations produced non-asymptotic species accumulation curves, suggesting that increased sampling effort would reveal new fungal species (Figure 3). The Chao and Bootstrap estimators of the maximum number of species did not approach an horizontal asymptote, what made them unreliable estimators for this particular case.

\section{Effect of Epichloë festucae on Root Endophytic Fungal Communities}

In the set of 105 plants analyzed, 69 were infected by Epichlö festucae $(\mathrm{E}+)$ and 36 were not $(\mathrm{E}-)$. Out of the 135 fungal species identified in all plants, 52 were exclusive of E+ plants, 29 of Eplants, and 54 occurred in both.

The ANOVA showed that neither the presence of Epichloë nor population had a significant effect on species richness $(F=1.999$; $p=0.276$ and $F=1.626 ; p=0.174$ respectively). The beta diversity index showed a similar trend, no significant differences were found between $\mathrm{E}+$ and $\mathrm{E}-$ plants $(p=0.989)$ or among populations ( $p=0.377$ for all pairwise comparisons). The values of the Shannon diversity index ( $\left.H^{\prime}\right)$ were relatively high, but similar for E+ and E- plants (Table 3).

Both E+ and E- plants displayed similar species accumulation curves when the data from all five populations were pooled (Figure 4A). The species richness accumulated at 36 plants was $80.93 \pm 5.24$ for $\mathrm{E}+$ plants and $72.03 \pm 1.04$ for

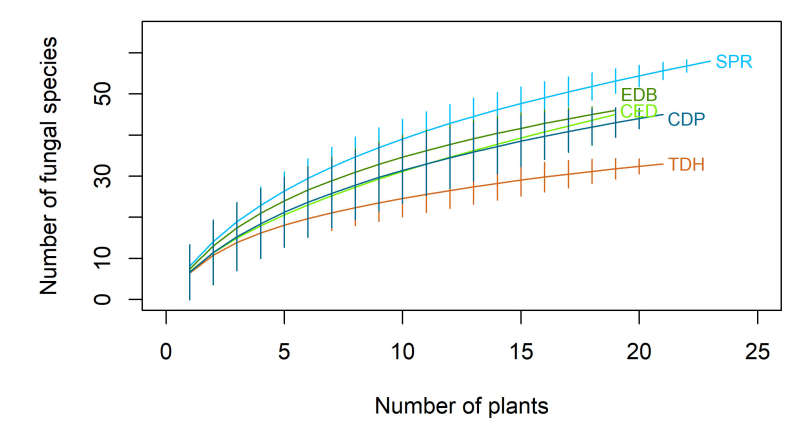

FIGURE 3 | Species accumulation curves for fungal species isolated from roots of Festuca rubra subsp. pruinosa at five populations from marine cliffs in northern Spain. TDH, Torre de Hércules; CED, Cedeira; EDB, Estaca de Bares; SPR, San Pedro de la Rivera; CDP, Cabo de Peñas.

TABLE 3 | Fungal species richness and diversity in roots of Festuca rubra subsp. pruinosa plants infected $(\mathrm{E}+)$ or not infected $(\mathrm{E}-)$ by Epichloë festucae at five populations in marine cliffs.

\begin{tabular}{lccccc}
\hline Factor & & $\begin{array}{c}\text { Number of } \\
\text { plants } \\
\text { analyzed }\end{array}$ & $\begin{array}{c}\text { Species per } \\
\text { plant }\end{array}$ & $\begin{array}{c}\text { B diversity } \\
\text { (Kolleff) }\end{array}$ & H' Shannon \\
\hline Epichloë & E+ & 69 & $7.19 \pm 2.63$ & $0.59 \pm 0.07$ & 4.04 \\
& E- & 36 & $7.08 \pm 3.11$ & $0.59 \pm 0.08$ & 3.90 \\
Population & TDH & 21 & $6.52 \pm 1.91$ & $0.51 \pm 0.10$ & 3.13 \\
& CED & 19 & $6.84 \pm 2.59$ & $0.50 \pm 0.10$ & 3.32 \\
& EDB & 22 & $7.47 \pm 2.55$ & $0.56 \pm 0.10$ & 3.48 \\
CDP & 20 & $6.67 \pm 3.45$ & $0.55 \pm 0.10$ & 3.59 \\
SPR & 23 & $8.17 \pm 3.04$ & $0.55 \pm 0.05$ & 3.43
\end{tabular}

E- plants. Within each population, we found small differences (both positive and negative) between $\mathrm{E}+$ and $\mathrm{E}-$ plants (Figures 4B-F).

The first two axes of the CCA were statistically significant $(p=0.001)$ and explained 35.18 and $29.36 \%$ of the variance. After the forward selection, only the variable population was finally included in the CCA and explained the 5.29\% of the variation. The CCA biplot showed no clear separation between $\mathrm{E}+$ and E- plants (Figure 5). However, there was a segregation among plant populations: the first axis clustered populations according to regions and separated the Asturian populations (CDP and $\mathrm{SPR}$ ) from the Galician ones (TDH, CED and EDB); and the second axis segregated both Asturian populations, suggesting that the structure of the root mycobiota of these two populations differ between them and with respect to the Galician populations (Figure 5). All the core and the abundant taxa were present in both E+ and E- plants, although some species were more abundant in $\mathrm{E}+$ (Slopeiomyces cylindrosporus) or in $\mathrm{E}-$ plants (Drechslera sp.) (Figure 6).

In terms of similarity of the fungal assemblages between pairs of populations, $J$ values were higher between populations from the same region, 0.238 to 0.362 among Galician populations and 0.238 between Asturian populations, than between Galician and Asturian populations, which ranged from 0.095 to 0.193 (Table 4).

\section{Salt Tolerance and Enzymatic Activity of Endophytic Fungi}

The salt tolerance assay showed that fungal strains had three different types of response in terms of their radial growth. Most strains analyzed (71.8\%) were halophilic, showing a statistically significant increase in radial growth in PDA plates containing $\mathrm{NaCl}$ respect to the control (Supplementary Table S2). The radial growth of $51.5 \%$ of these halophilic strains increased at both $\mathrm{NaCl}$ concentrations; that of $21.2 \%$ increased only in $600 \mathrm{mM}$ $\mathrm{NaCl}$, and that of $27.3 \%$ increased only in $300 \mathrm{mM} \mathrm{NaCl}$. All nine Fusarium strains and four of the five Diaporthe sp. A strains tested were halophylic.

Some strains (6.5\%) were halotolerant, not showing a significant difference in radial growth in $300 \mathrm{mM}$ and $600 \mathrm{mM}$ $\mathrm{NaCl}$ with respect to the control. Finally, $21.7 \%$ of the strains showed a radial growth decrease in culture media containing $\mathrm{NaCl}$ and were classified as halosensitive, $80.0 \%$ of these strains decreased only in $600 \mathrm{mM} \mathrm{NaCl}$, and the remaining $20.0 \%$ did it at both salt concentrations. Within taxa like Diaporthe sp. A, Periconia macrospinosa or Penicillium sp. F, some strains had different responses, i.e., Diaporthe strain S129 was halophilic and strain S69 halosensitive (Supplementary Table S2).

The nine E. festucae strains tested were halosensitive, all decreased in radial growth in the $600 \mathrm{mM}$ medium (Table 5). Seven of them did not show a significant difference in radial growth with respect to the control at $300 \mathrm{mM} \mathrm{NaCl}$.

Cellulase and amylase activities were assayed for 43 fungal strains (Table 6). Twenty three of these strains, including all tested strains of Fusarium oxysporum, Penicillium and Helotiales sp. A, showed cellulase activity in vitro. In contrast, none of the 

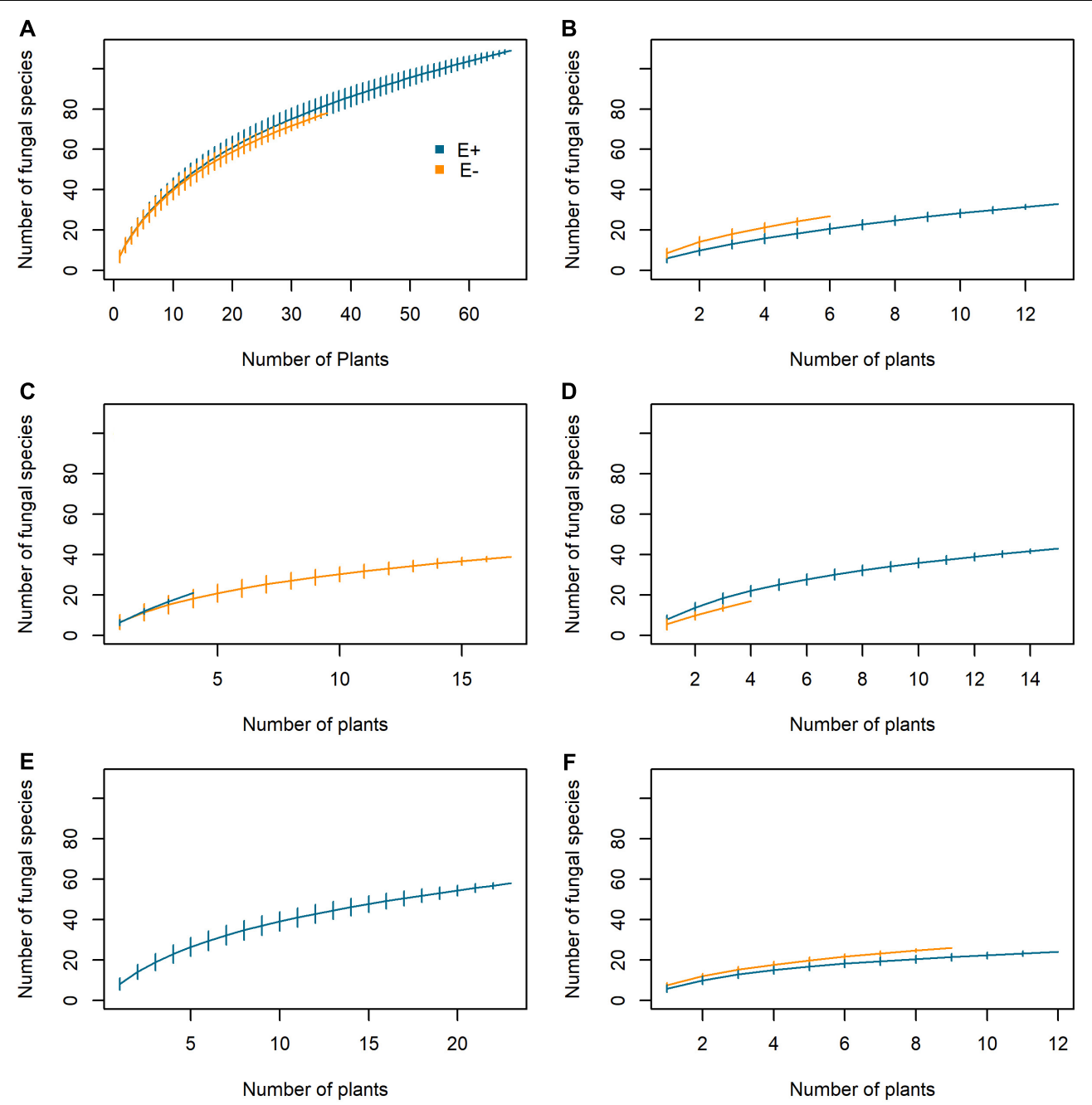

FIGURE 4 | Species accumulation curves of root mycobiota in Epichloë festucae infected (E+) and non-infected (E-) plants of Festuca rubra subsp. pruinosa from five marine cliff populations in northern Spain. (A) Whole plant set; (B) Cedeira; (C) Cabo de Peñas; (D) Estaca de Bares; (E) San Pedro de la Rivera; (F) Torre de Hércules.

six Diaporthe sp. A strains tested was positive. Amylase activity was detected in only nine strains, including all four Penicillium strains tested.

\section{Effect of FRP Endophytes on Growth of Lolium perenne}

A two-way ANOVA showed a significant effect of salinity $\left(p=0.004 ; \bar{X}_{\text {control }}=0.236 \mathrm{~g}, \overline{\mathrm{X}}_{\mathrm{NaCl}}=0.192 \mathrm{~g}\right)$, endophyte inoculated $\left(p<0.001 ; \overline{\mathrm{X}}_{\text {control }}=0.194 \mathrm{~g}, \overline{\mathrm{X}}_{\text {Periconia }}=0.231 \mathrm{~g}\right.$, $\overline{\mathrm{X}}_{\text {Penicillium }}=0.109, \overline{\mathrm{X}}_{\text {Diaporthe }}=0.321 \mathrm{~g}$ ), and their interaction ( $p=0.034$; Figure 7 ) on dry matter production of $L$. perenne. Plants inoculated with Diaporthe S69, a Diaporthe sp. A strain, showed a significant increase in biomass production with respect to the uninoculated control plants in both watering treatments: $31.3 \%$ in tap water and $48.9 \%$ under saline irrigation (Figure 7). The plants inoculated with Periconia S6 had greater biomass in both watering treatments, but the difference respect to the controls was not significant. In contrast, plants inoculated with Penicillium E7 did not show visual symptoms of stress such as dry leaves, but showed a significant decrease in biomass production under the tap water treatment; in the salinity treatment the difference in biomass was not significant with respect to uninoculated plants. In addition, the biomass of plants inoculated with Penicillium E7 did not differ between tap water and salinity treatments.

Sodium was significantly affected by salt $(p<0.001)$, endophyte inoculated $(p<0.001)$ and their interaction $(p=0.002)$. Inoculated plants with Periconia S6 and Diaporthe S69 strains had greater $\mathrm{Na}$ than controls under tap water treatment (Figure 7). When plants were salt irrigated, the increase in Na was greater in plants inoculated with E7, S6 or S69 strains than in control plants. Potassium content was significantly affected by salt $(p=0.038)$, endophyte inoculated $(p<0.001)$ and their interaction $(p=0.003)$. Inoculated plants with E7, S6 or S69 


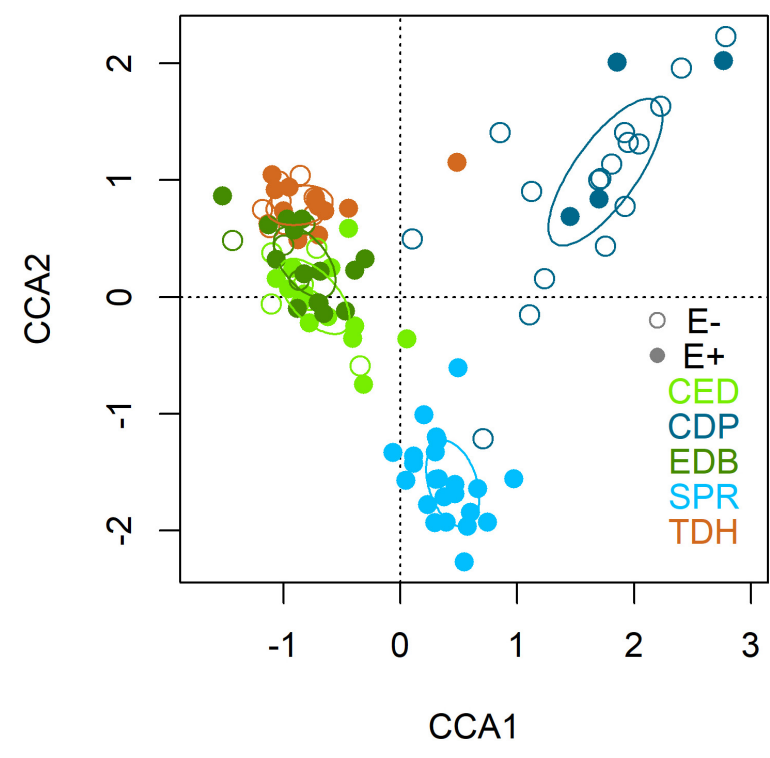

FIGURE 5 | Canonical correspondence analysis (CCA) of the fungal endophyte community composition of roots of Festuca rubra subsp. pruinosa from marine cliffs according to the presence $(E+)$ or absence $(E-)$ of Epichloë festucae, and population (CED, Cedeira; CDP, Cabo de Peñas; EDB, Estaca de Bares; SPR, San Pedro de la Rivera; TDH, Torre de Hércules).

strains had significantly greater $\mathrm{K}$ concentration than controls at water treatment (Figure 7). At salt treatment, plants inoculated with Penicillium E7 had the greatest K content.

After the harvest, root fragments of Lolium perenne were plated on culture media and the fungal isolates obtained were identified through morphological characteristics as the endophytes inoculated into the plants. The reisolation of these fungi indicated their compatibility with $L$. perenne and the success of plant inoculation.

\section{DISCUSSION}

\section{The Core Microbiome of Festuca rubra subsp. pruinosa}

The roots of Festuca rubra subsp. pruinosa were found to be a niche containing numerous fungal species, an assemblage of 135 culturable species was identified. This magnitude is not unusual in surveys of the mycobiota of grasses (Sánchez Márquez et al., 2012), but the high incidence of seven species that were present in more than $20 \%$ of the plants, and in several populations is remarkable. These species were Fusarium oxysporum, Diaporthe sp. A, Fusarium sp. A, Helotiales sp. A, Drechslera sp., Slopeiomyces cylindrosporus, and Penicillium sp. F. In particular, Fusarium oxysporum and Diaporthe sp. A occurred in more than $50 \%$ of the plants, and at all five populations examined. Those seven fungal species seem to be components of the core microbiome of FRP, because they are shared by a significant number of plants, and occur at different populations (Shade and Handelsman, 2012). It is not common to find a group of fungal species with such high incidence within and among plant populations. Using similar methodology, as well as culture independent methods, no more than two or three species with an incidence greater than 20\% were found in surveys of other grasses (Sánchez Márquez et al., 2008, 2010; Ofek-Lalzar et al., 2016; Zhong et al., 2018). In addition, dominant species reported in several taxa of inland grasses, such as Cladosporium or Epicoccum, were absent from FRP plants (Peláez et al., 1998; Sánchez Márquez et al., 2012; Ofek-Lalzar et al., 2016).

Two of the core taxa of FRP belonged to the genus Fusarium. Although this genus is best known due to important pathogens of numerous agricultural species, it is also one of the most commonly isolated genera of endophytes from grasses and other plants (Vázquez de Aldana et al., 2013; Martins et al., 2016; Lofgren et al., 2018). Research on endophytic Fusarium has shown that some strains can improve the salinity tolerance of their host plants (Rodriguez and Redman, 2008; Redman et al., 2011). Furthermore, F. oxysporum strains obtained from FRP plants in this study were found to protect tomato plants against a pathogenic strain of $F$. oxysporum f.sp. lycopersici (Constantin et al., 2017).

The genus Diaporthe contains numerous species that behave as endophytes or pathogens, and in some cases as both, depending on the host plant species (Gomes et al., 2013). Diaporthe sp. A is a main component of the core microbiome of FRP, and species of this genus have also been reported as dominant components of the microbiome of olive and other plants (Martins et al., 2016; Noriler et al., 2018). Regarding mutualism, Diaporthe strains originally isolated from wild plant species promoted the growth of rice and tritordeum (Yang et al., 2015; Zabalgogeazcoa et al., 2018).

Our work revealed that associations between DSE and FRP roots are common in sea cliffs. Some of the core and most abundant taxa, such as Darksidea sp., Periconia macrospinosa, Slopeiomyces cylindrosporus and Drechslera sp., were previously reported as DSE in other grasses (Hornby et al., 1977; Knapp et al., 2012, 2015; Siless et al., 2018). In addition, Helotiales sp. A also seems to be a DSE because its hyphae had characteristics of this group, and other members of the Helotiales (i.e., Phialocephala fortinii) are recognized as DSE (Sieber and Grünig, 2013; Ridout et al., 2017). DSE colonize roots of plants communities in different habitats, and some authors hypothesized that these fungi can play an important role in plant adaptation to abiotic stress conditions, especially drought (Porras-Alfaro et al., 2008; Knapp et al., 2015). However, in spite of their abundance in nature, there is still uncertainty about the ecological significance of plant-DSE symbioses (Mandyam and Jumpponen, 2014).

Given the characteristics of the FRP habitat, strains from taxa belonging to the core microbiome of FRP are excellent candidates to test their possible role in host plant adaptation to salinity. Habitat-adapted symbiosis is a phenomenon which occurs when plants establish relationships with symbionts which enhance their adaptation to a particular stress factor present in their habitat (Rodriguez and Redman, 2008). Whether this occurs in the plant-endophyte systems here described would require inoculation of FRP seedlings and evaluation of plant performance 


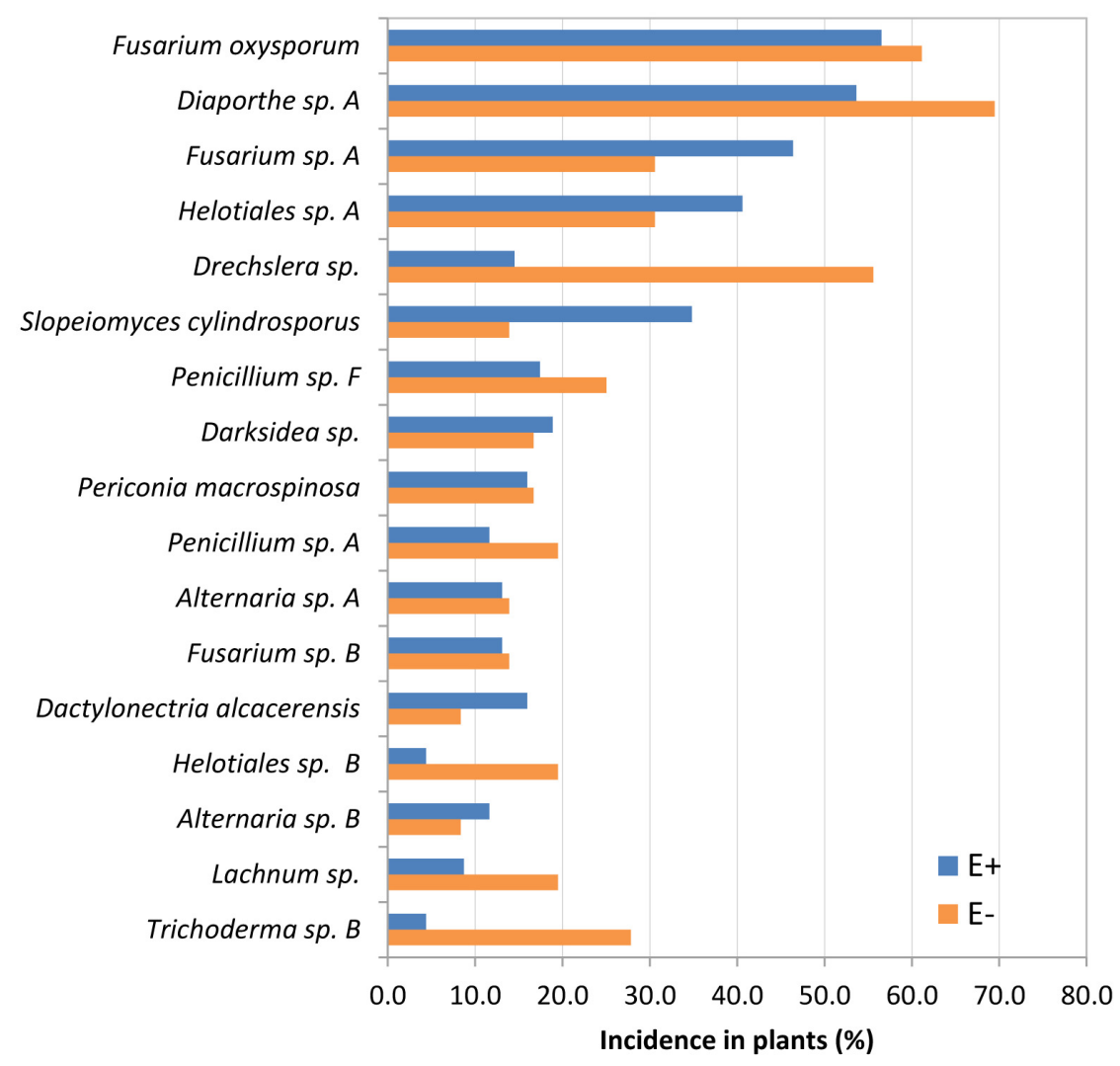

FIGURE 6 | Incidence in plants of Festuca rubra subsp. pruinosa from marine cliffs infected (E+) and not infected (E-) by Epichloë festucae of root species that constitute the core and abundant classes of the culturable mycobiome.

TABLE 4 | Jaccard index of similarity (bold) and number of fungal species identified in roots of each pair of populations (italic) of Festuca rubra subsp. pruinosa plants from marine cliffs.

\begin{tabular}{lccccc}
\hline Population & TDH & CED & EDB & SPR & CDP \\
\hline TDH & $\mathbf{1 . 0 0 0}$ & $\mathbf{0 . 2 3 8}$ & $\mathbf{0 . 3 6 2}$ & $\mathbf{0 . 0 9 5}$ & $\mathbf{0 . 1 4 7}$ \\
CED & 63 & $\mathbf{1 . 0 0 0}$ & $\mathbf{0 . 3 0 0}$ & $\mathbf{0 . 1 8 2}$ & $\mathbf{0 . 1 5 4}$ \\
EDB & 58 & 70 & $\mathbf{1 . 0 0 0}$ & $\mathbf{0 . 1 9 3}$ & $\mathbf{0 . 1 8 2}$ \\
SPR & 84 & 88 & 88 & $\mathbf{1 . 0 0 0}$ & $\mathbf{0 . 2 3 8}$ \\
CDP & 68 & 78 & 77 & 84 & $\mathbf{1 . 0 0 0}$ \\
\hline
\end{tabular}

parameters under salinity stress. The search for endophytes from the core microbiome of wild plants adapted to unhospitable habitats has produced interesting solutions for the improvement of stress tolerance on agronomic crops (Redman et al., 2011; Ali et al., 2018).

Because of our research interest in culturable fungi, and the isolation methods used, components of the plant microbiome such as bacteria or non-culturable fungi were not identified in this survey. Members of these groups could have an important role in the adaptation of FRP plants to marine cliffs. For instance, symbioses with arbuscular mycorrizal fungi (AMF) can contribute to plant growth and protection under environmental stress (Lenoir et al., 2016). Symbiotic associations with AMF have been reported for some Festuca species (i.e.,
Dalpé and Aiken, 1998; Santos et al., 2006), but their presence and effects in FRP were not studied, and deserve attention.

In this work, about $72 \%$ of the fungal strains from FRP roots were classified as halophilic, their radial growth in vitro increased in the presence of $\mathrm{NaCl}$. This category included some species of the core microbiome of FRP, like Diaporthe sp. A, Fusarium oxysporum, Fusarium sp. A, and Helotiales sp. A. In contrast, E. festucae showed a halosensitive response. The life cycle of this fungus which colonizes the intercellular space of aerial tissues and is seed transmitted, can be completely endophytic. Thus, host plants protect the fungus from the harmful saline environment. However, other fungal species which spend a part of their life cycle outside of their plant hosts might benefit from being halotolerant.

Cellulase or amylase enzymatic activity in vitro was detected in some of the core taxa, such as Fusarium oxysporum, Helotiales sp. A and Penicillium sp. F. These enzymes degrade cellulose and starch to soluble sugars such as glucose, cellobiose, and other oligomers which can be readily absorbed by plant roots (Carroll et al., 1983). Considering that FRP plants grow in rock fissures where soil and nutrients are very scarce, fungi with these enzymatic activities could have a role recycling nutrients from dead roots. However, these two enzymatic activities were not detected in cultures of Slopeiomyces cylindrosporus, a fungus with saprobic capability (Hornby et al., 1977), and cellulase activity 
TABLE 5 | Radial growth of nine Epichloë festucae strains isolated from Festuca rubra subsp. pruinosa plants from marine cliffs in PDA plates with different NaCl concentrations.

\begin{tabular}{|c|c|c|c|c|c|c|c|}
\hline \multirow[t]{2}{*}{ Strain } & \multicolumn{3}{|c|}{ Radial growth (cm) } & \multicolumn{4}{|c|}{ Type of response } \\
\hline & $0 \mathrm{mM}$ & $300 \mathrm{mM}$ & $600 \mathrm{mM}$ & & & & \\
\hline $\mathrm{TDH} 1$ & $2.12 \mathrm{ab}$ & $2.40 \mathrm{~b}$ & $1.60 \mathrm{a}$ & Halosensitive & & & \\
\hline TDH11 & $1.97 \mathrm{ab}$ & $2.42 \mathrm{a}$ & $1.82 \mathrm{~b}$ & Halosensitive & & & \\
\hline $\mathrm{TDH}$ & $2.67 \mathrm{a}$ & $2.60 \mathrm{a}$ & $1.62 b$ & Halosensitive & & & \\
\hline CED6 & $2.67 \mathrm{a}$ & $2.17 \mathrm{ab}$ & $1.43 \mathrm{~b}$ & Halosensitive & & & \\
\hline CED12 & $2.43 \mathrm{a}$ & $2.37 \mathrm{a}$ & $1.55 b$ & Halosensitive & & & \\
\hline CED10 & $2.48 \mathrm{a}$ & $2.40 \mathrm{a}$ & $1.32 \mathrm{~b}$ & Halosensitive & & & \\
\hline CED1 & $2.42 \mathrm{a}$ & $2.33 \mathrm{a}$ & $1.42 \mathrm{~b}$ & Halosensitive & 0 & 300 & $600 \mathrm{mM}$ \\
\hline EDB9 & $2.37 \mathrm{a}$ & $1.25 b$ & $0.67 \mathrm{c}$ & Halosensitive & & & \\
\hline EDB11 & $2.85 \mathrm{a}$ & $1.65 b$ & $0.68 \mathrm{c}$ & Halosensitive & & & \\
\hline
\end{tabular}

For each row different letters indicate significant differences at $p<0.05$.

was absent form Diaporthe sp. A strains. This result could be due to non-induction of these enzymes in the culture medium used, because both fungal strains grew well as saprobes in a beet pulp medium, rich in carbohydrate and protein, which was used to prepare inoculum for plant inoculations.

\section{Potential of FRP Endophytes for Plant Improvement}

Knowledge about the role of endophytic fungi on plant adaptation to salinity stress is important because the world surface of saline soils is increasing, producing economic losses in crops (Munns and Gilliham, 2015). Diaporthe sp. A strain S69 improved the growth of plants of Lolium perenne, an important forage grass, in the presence and absence of salinity stress. On average, plants inoculated with Diaporthe S69 produced $31 \%$ more aerial biomass than the uninoculated controls under normal conditions, and $49 \%$ more under salinity stress. Similarly, fungal endophytes such as Piriformospora indica, Fusarium culmorum, or Penicillium minioluteum can alter physiological processes and improve tolerance to salt stress in agricultural crop species (Baltruschat et al., 2008; Khan et al., 2011; Redman et al., 2011).

One of the indirect consequences of salinity is an enrichment of $\mathrm{Na}$ and deficiency of $\mathrm{K}$ in plant cells, caused by the competition between $\mathrm{Na}$ and $\mathrm{K}$, that have similar ionic radii and ion hydration energies (Munns and Tester, 2008). We found that L. perenne plants inoculated with Periconia S6, Penicillium E7 and Diaporthe S69 strains accumulated significantly more $\mathrm{K}$ in aboveground tissues under the tap water treatment than uninoculated plants; this suggests that an enrichment of $\mathrm{Na}$ due to salinity might have been prevented by the increased $\mathrm{K}$ content present before the stress. Similar results were observed in grasses inoculated with Aspergillus aculeatus (Xie et al., 2017) suggesting that the maintenance of a high level of $\mathrm{K}$ may contribute the alleviation of the negative effect of sodium. A beneficial effect of $\mathrm{K}$ accumulation in plants has also been reported for associations with arbuscular mycorrhiza (Langenfeld-Heyser et al., 2007) and Epichloë spp. (Chen et al., 2018). It is important to point out that the increase in biomass of $L$. perenne plants inoculated with
Diaporthe strain S69 occurred not only during salt treatment but also in the tap water treatment. This implies that the fungal effect improving plant growth was not a specific process induced by salinity. To study the effect of fungal strains on plant parameters which can be altered by endophytes to improve plant performance, such as phytohormones, photosynthetic capacity, nutrient absorption or antioxidant capability (Baltruschat et al., 2008; Redman et al., 2011; Leitão and Enguita, 2016) is a future objective of our research.

\section{Effect of Epichloë festucae, an Aboveground Tissue Endophyte, on Root Mycobiota}

The incidence of Epichlöe festucae in FRP populations was $65.7 \%$, a value very similar to that of $69 \%$ observed in a previous survey that included the same populations from Galicia (Zabalgogeazcoa et al., 2006). The relatively high incidence of E. festucae suggests that in an unhospitable habitat like sea cliffs, the costs of harboring a systemic symbiont could be compensated by mutualism. However, endophyte incidences closer to $100 \%$ could be expected under such circumstances. Whether natural selection favoring E+ plants, the efficiency of seed transmission, or a combination of both processes are involved in the prevalence rates of Epichloë observed in FRP populations is unknown, and deserves further study. Imperfect seed transmission $(<100 \%)$ has been reported in other grass - Epichloë systems (Gundel et al., 2009). High incidence of Epichloë festucae in Festuca rubra populations has been reported in semiarid grasslands (70\%) (Zabalgogeazcoa et al., 1999), or in the Scottish islands of St. Kilda (80\%) (Bazely et al., 1997). In contrast, in Finland only 9 of 49 infected F. rubra populations had frequencies greater than 50\% (Wali et al., 2007), and no plants harboring Epichloë were found in populations from subarctic regions of Canada (Santangelo and Kotanen, 2016).

In some grass-endophyte associations Epichloë species could play a key role in salt tolerance. In pot experiments Epichloë coenophiala increased the root biomass of tall fescue (Schedonorus arundinaceous) (Sabzalian and Mirlohi, 2010), and another Epichloë species increased the shoot and root biomass 
TABLE 6 | Cellulase and amylase activity in fungal strains isolated from roots Festuca rubra subsp. pruinosa plants from marine cliffs.

\begin{tabular}{|c|c|c|c|}
\hline ID & Endophyte & $\begin{array}{c}\text { Cellulase } \\
\text { activity }\end{array}$ & $\begin{array}{c}\text { Amylase } \\
\text { activity }\end{array}$ \\
\hline T16 & Alternaria sp. A & - & ++ \\
\hline C115 & Alternaria sp. B & - & + \\
\hline T90 & Codinaeopsis sp. & ++ & - \\
\hline $\mathrm{C} 2$ & Dactylonectria alcacerensis & - & - \\
\hline $\mathrm{C} 1$ & Darksidea sp. & + & - \\
\hline $\mathrm{C} 7$ & Darksidea sp. & + & - \\
\hline CP36 & Diaporthe sp. A & - & - \\
\hline EB4 & Diaporthe sp. A & - & - \\
\hline S129 & Diaporthe sp. A & - & + \\
\hline S32 & Diaporthe sp. A & - & - \\
\hline S69 & Diaporthe sp. A & - & - \\
\hline $\mathrm{T} 18$ & Diaporthe sp. A & - & - \\
\hline $\mathrm{CP} 1$ & Drechslera sp. & - & - \\
\hline E71 & Drechslera sp. & - & - \\
\hline $\mathrm{T} 41$ & Drechslera sp. & - & - \\
\hline T50 & Drechslera sp. & - & - \\
\hline CD8 & Epichloë festucae & - & - \\
\hline $\mathrm{S} 13$ & Fusarium sp. A & + & - \\
\hline $\mathrm{T} 112$ & Fusarium sp. A & + & - \\
\hline T6 & Fusarium sp. A & + & - \\
\hline $\mathrm{C} 70$ & Fusarium sp. B & + & - \\
\hline S38 & Fusarium sp. B & + & + \\
\hline CP3 & Fusarium oxysporum & ++ & - \\
\hline $\mathrm{S} 10$ & Fusarium oxysporum & + & ++ \\
\hline SP8 & Fusarium oxysporum & + & - \\
\hline $\mathrm{T} 150$ & Fusarium oxysporum & + & - \\
\hline E79 & Helotiales sp. B & +++ & - \\
\hline$S 74$ & Lachnum sp. & - & - \\
\hline C44 & Helotiales sp. A & ++ & - \\
\hline S75 & Helotiales sp. A & ++ & - \\
\hline $\mathrm{T} 141$ & Helotiales sp. A & ++ & - \\
\hline T29 & Helotiales sp. A & + & - \\
\hline T3 & Helotiales sp. A & ++ & - \\
\hline $\mathrm{T} 114$ & Penicillium sp. F & ++ & +++ \\
\hline C13 & Penicillium sp. A & + & + \\
\hline E7 & Penicillium sp. A & +++ & + \\
\hline T59 & Penicillium sp. A & ++ & + \\
\hline S6 & Periconia macrospinosa & - & - \\
\hline $\mathrm{T} 131$ & Periconia macrospinosa & - & - \\
\hline C43 & Slopeiomyces cylindrosporus & - & - \\
\hline S5 & Slopeiomyces cylindrosporus & - & - \\
\hline $\mathrm{T} 70$ & Slopeiomyces cylindrosporus & - & - \\
\hline CP17 & Trichoderma sp. B & ++ & - \\
\hline
\end{tabular}

(-) No enzymatic activity; (+) Slight activity; halo < $3 \mathrm{~mm}$. (++) Moderate activity; halo $<5 \mathrm{~mm}$. (+++) High activity; halo $>5 \mathrm{~mm}$.

of wild barley (Hordeum brevisubulatum) under salinity stress (Song et al., 2015; Chen et al., 2018). In contrast, in FRP plants no significant effect of Epichloë on shoot dry weight was detected under salt treatment, although root growth or other parameters that could be affected by the presence of E. festucae under salinity were not analyzed (Zabalgogeazcoa et al., 2006). Nevertheless,

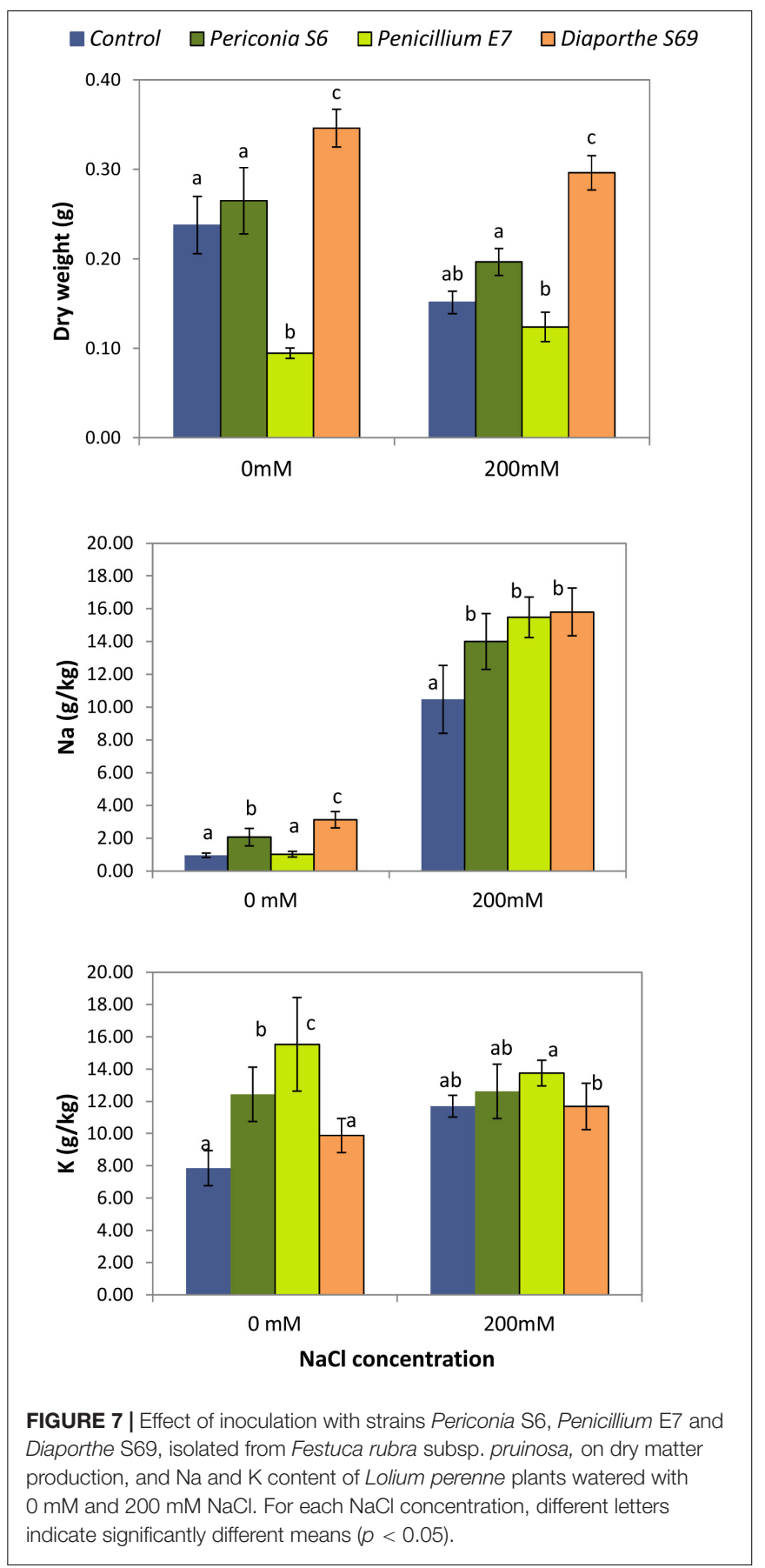

in a stressful habitat like sea cliffs, environmental pressure on a holobiont might not necessarily affect an individual endophyte, but an assemblage where interactions among the plant host and the eukaryotic and prokaryotic microbiome components might be complex.

The presence of Epichloë in aboveground tissues of the host plant can affect underground processes by altering rhizospheric conditions that affect the density and activity of soil microorganisms (Omacini et al., 2012). This may result from endophyte effects on root exudates that can act as 
chemical attractants or repellents in the rhizosphere (Malinowski et al., 1998). For instance, phenolic compounds are microbial inhibitors, and they increase in roots due to the presence of Epichlö̈ (Ponce et al., 2009; Vázquez de Aldana et al., 2011). The effect of Epichlö on arbuscular mycorrhizal fungi has been extensively studied, and reduction, promotion, and null effects have been reported (Omacini et al., 2006; Novas et al., 2012; Rojas et al., 2016). Our results indicate that E. festucae did not have a clear and significant effect on the composition of the core microbiome or other mycobiota from FRP roots, although changes in the abundance of some species were found. These results are in agreement with other studies where the presence of Epichloë did not alter fungal colonization in roots (Vandegrift et al., 2015; Slaughter and McCulley, 2016) or shoots (Zabalgogeazcoa et al., 2013). Nevertheless, Zhong et al. (2018) reported that the presence of Epichloë decreased the diversity of root-associated fungi in Achnatherum inebrians and changed the community composition. However, such changes were in fungal orders with an abundance lower than $10 \%$, where the number of isolates of these taxa can be low.

\section{CONCLUSION}

In conclusion, this study shows that numerous species of culturable fungi are associated to the roots of Festuca rubra subsp. pruinosa in its sea cliff habitat. Within this fungal assemblage of 135 species, a set of seven species occurred in a relatively high number of plants and locations, and those seem to be components of the core mycobiome of FRP: Fusarium oxysporum, Diaporthe sp. A, Fusarium sp. A, Helotiales sp. A, Drechslera sp., Slopeiomyces cylindrosporus, and Penicillium sp. F. Strains of these species are very promising candidates to study their role in the adaptation of FRP plants to salinity, a characteristic stress factor of their habitat. Furthermore, a Diaporthe strain belonging to the core taxa significantly improved the growth of Lolium perenne plants under normal and salinity stress conditions, showing the potential of the FRP core microbiome for the improvement of agricultural crops.

\section{REFERENCES}

AEMET (2012). Guía Resumida del Clima en España 1981-2010. Gobierno de España. Available at: http://www.aemet.es/es/serviciosclimaticos/ datosclimatologicos/valoresclimatologicos

Ali, A. H., Abdelrahman, M., Radwan, U., El-Zayat, S., and El-Sayed, M. A. (2018). Effect of Thermomyces fungal endophyte isolated from extreme hot desert-adapted plant on heat stress tolerance of cucumber. Appl. Soil Ecol. 124, 155-162. doi: 10.1016/j.apsoil.2017.11.004

Baltruschat, H., Fodor, J., Harrach, B. D., Niemczyk, E., Barna, B., and Gullner, G. (2008). Salt tolerance of barley induced by the root endophyte Piriformospora indica is associated with a strong increase in antioxidants. New Phytol. 180, 501-510. doi: 10.1111/j.1469-8137.2008.02 583.x

Bazely, D. R., Vicari, M., Emmerich, S., Filip, L., Lin, D., and Inman, A. (1997). Interactions between herbivores and endophyte-infected Festuca rubra from the Scottish islands of St. Kilda, Benbecula and Rum. J. Appl. Ecol. 34, 847-860. doi: $10.2307 / 2405276$

\section{AUTHOR CONTRIBUTIONS}

EP collected the plants, isolated and identified fungi, made the experiments, and analyzed the data. BA designed the experiments, participated in plant collection, and analyzed the data. LS made the statistical analyses. IZ supervised the research, helped to sample plants, designed the experiments and analyzed the data. EP, BA, and IZ wrote the article.

\section{FUNDING}

This study has received funding from the European Union's Horizon 2020 Research and Innovation Program under the Marie Skłodowska-Curie grant agreement no. 676480. LS was funded through a Talent Recruitment grant from "Obra Social La CaixaFundación CAN". We acknowledge support of the publication fee by the CSIC Open Access Publication Support Initiative through its Unit of Information Resources for Research (URICI).

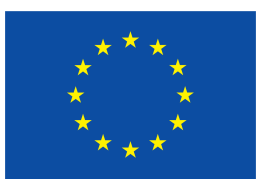

\section{ACKNOWLEDGMENTS}

Martijn Rep and Maria Constantin, from the University of Amsterdam, helped to identify Fusarium oxysporum strains. The technical help of María José Cuesta and César Paredero are acknowledged.

\section{SUPPLEMENTARY MATERIAL}

The Supplementary Material for this article can be found online at: https://www.frontiersin.org/articles/10.3389/fmicb. 2018.03321/full\#supplementary-material

Carroll, G., Petrini, G., and Petrini, O. (1983). Patterns of substrate utilization by some endophytes from coniferous foliage. Mycologia 75, 53-63. doi: 10.2307/ 3792923

Chen, T., Johnson, R., Chen, S., Lu, H., Zhou, J., and Li, C. (2018). Infection by the fungal endophyte Epichloë bromicola enhances the tolerance of wild barley (Hordeum brevisubulatum) to salt and alkali stresses. Plant Soil 428, 353-370. doi: 10.1007/s11104-0183643-4

Clay, K., and Schardl, C. (2002). Evolutionary origins and ecological consequences of endophyte symbiosis with grasses. Am. Natur. 60, S99-S127. doi: 10.1086/ 342161

Colwell, R. K. (2005). EstimateS: Statistical Estimation of Species Richness and Shared Species From Samples. Version 7.5. Available at: http://purl.oclc.org/ estimates.

Constantin, M. E., de Lamo, F., Takken, F., and Rep, M. (2017). "Fusarium oxysporum and its biocontrol," in Proceedings of the Book of abstracts of the 29th Fungal Genetics Conference (2017 March14-19) (Pacific Grove, CA: Genetics Society of America), 238. 
Dalpé, Y., and Aiken, S. G. (1998). Arbuscular mycorrhizal fungi associated with Festuca species in the Canadian High Artic. Can. J. Bot. 76, 1930-1938. doi: 10.1139/b98-165

Doody, J. P. (2001). "Sea cliffs and sea cliff vegetation," in Coastal Conservation and Management. An Ecological Perspective. Conservation Biology series, Vol. 13, ed. J. P. Doody (Berlin: Springer Science), 25-52.

Gomes, R. R., Glienke, C., Videira, S. I. R., Lombard, L., Groenewald, J. Z., and Crous, P. W. (2013). Diaporthe: a genus of endophytic, saprobic and plant pathogenic fungi. Persoonia 31, 1-41. doi: 10.3767/003158513X666844

Gundel, P. E., Garibaldi, L. A., Tognetti, P. M., Aragon, R., Ghersa, C. M., and Omacini, M. (2009). Imperfect vertical transmission of the endophyte Neotyphodium in exotic grasses in grasslands of the flooding Pampa. Microb. Ecol. 57, 740-748. doi: 10.1007/s00248-008-9447-y

Hankin, L., and Anagnostakis, S. L. (1975). The use of solid media for detection of enzyme production by fungi. Mycologia 67, 597-607. doi: 10.2307/3758395

Hornby, D., Slope, D. B., Gutteridge, R. J., and Sivanesan, A. (1977). Gaeumannomyces cylindrosporus, a new ascomycete from cereal roots. Trans. Br. Mycol. Soc. 69, 21-25.

Humpreys, M. O. (1982). The genetic basis of tolerance to salt spry in popultions of Festuca rubra L. New Phytol. 91, 287-296. doi: 10.1111/j.1469-8137.1982. tb03313.x

Jaccard, P. (1912). The distribution of the flora in the alpine zone. New Phytol. 11, 37-50.

Khan, A., Hamayun, M., Ahmad, N., Hussain, J., Kang, S., Kim, Y., et al. (2011). Salinity stress resistance offered by endophytic fungal interaction between Penicillium minioluteum LHL09 and Glycine max, L. J. Microbiol. Biotechnol. 21, 893-902. doi: 10.4014/jmb.1103.03012

Knapp, D., Kovacs, G., Zajta, E., Groenewald, J., and Crous, P. (2015). Dark septate endophytic pleosporalean genera from semiarid areas. Persoonia 35, 87-100. doi: $10.3767 / 003158515 X 687669$

Knapp, D., Pintye, A., and Kovács, G. (2012). The dark side is not fastidious - Dark septate endophytic fungi of native and invasive plants of semiarid sandy areas. PLoS One 7:e32570. doi: 10.1371/journal.pone.0032570

Koleff, P., Gaston, K. J., and Lennon, J. J. (2003). Measuring beta diversity for presence-absence data. J. Anim. Ecol. 72, 367-382. doi: 10.1046/j.1365-2656. 2003.00710.x

Langenfeld-Heyser, R., Gao, J., Ducic, T., Tachd, P., Lu, C. F., Fritz, E., et al. (2007). Paxillus involutus mycorrhiza attenuate $\mathrm{NaCl}$-stress responses in the salt-sensitive hybrid poplar Populus $\times$ Canescens. Mycorrhiza 17, 121-131. doi: 10.1007/s00572-006-0084-3

Leitão, A. L., and Enguita, F. J. (2016). Gibberellins in Penicillium strains: challenges for endophyte-plant host interactions under salinity stress. Microbiol. Res. 183, 8-18. doi: 10.1016/j.micres.2015.11.004

Lenoir, I., Fontaine, J., and Sahraoui, A. (2016). Arbuscular mycorrhizal fungal responses to abiotic stresses: a review. Phytochemistry 123, 4-15. doi: 10.1016/j. phytochem.2016.01.002

Lepš, J., and Šmilauer, P. (2003). Multivariate Analysis of Ecological Data Using CANOCO. Cambridge: Cambridge University Press.

Leuchtmann, A., Schardl, C. L., and Siegel, M. R. (1994). Sexual compatibility and taxonomy of a new species of Epichloë symbiotic with fine fescue grasses. Mycologia 8, 6802-6812. doi: 10.2307/3760595

Lofgren, L. A., LeBlanc, N. R., Certano, A. K., Nachtigall, J., LaBine, K. M., Riddle, J., et al. (2018). Fusarium graminearum: pathogen or endophyte of North American grasses? New Phytol. 217, 1203-1212. doi: 10.1111/nph.14894

López-Bedoya, J. L., and Pérez-Alberti, A. (2009). "1230 Acantilados con vegetación de las costas atlánticas y bálticas," in Bases Ecológicas Preliminares para la Conservación de los Tipos de Hábitat de Interés Comunitario en España (Madrid: Ministerio de Medio Ambiente, y Medio Rural y Marino), 1-144.

Malinowski, D. P., Alloush, G. A., and Belesky, D. P. (1998). Evidence for chemical changes on the root surface of tall fescue in response to infection with the fungal endophyte Neotyphodium coenophialum. Plant Soil 205, 1-12. doi: 10.1023/A: 1004331932018

Mandyam, K., and Jumpponen, A. (2014). "Unraveling the dark septate endophyte functions: insights from the Arabidopsis model," in Advances in Endophytic Research, eds V. C. Verma and A. C. Gange (India: Springer), 115-141. doi: 10.1007/978-81-322-1575-2_6
Markgraf-Dannenberg, I. (1980). 'Festuca L', in Flora Europaea, eds T. G. Tutin, V. H. Heywood, N. A. Burges, D. M. Moore, D. H. Valentine, S. M. Walters et al. (Cambridge: University Press), 125-153.

Martínez Sagarra, G., Abad, P., and Devesa, J. A. (2017). Study of the leaf anatomy in cross-section in the Iberian species of Festuca L. (Poaceae) and its systematic significance. PhytoKeys 83, 43-74. doi: 10.3897/phytokeys.83.13746

Martins, F., Pereira, J. A., Bota, P., Bento, A., and Baptista, P. (2016). Fungal endophyte communities in above- and belowground olive tree organs and the effect of season and geographic location on their structures. Fungal Ecol. 20, 193-201. doi: 10.1016/j.funeco.2016.01.005

Munns, R., and Gilliham, M. (2015). Salinity tolerance of crops - What is the cost? New Phytol. 208, 668-673. doi: 10.1111/nph.13519

Munns, R., and Tester, M. (2008). Mechanisms of salinity tolerance. Ann. Rev. Plant Biol. 59, 651-681. doi: 10.1146/annurev.arplant.59.032607.092911

NCBI (2004). Using BLASTClust to Make Non-Redundant Sequence Sets. NCBI News. Available at: https://www.ncbi.nlm.nih.gov/Web/Newsltr/Spring04/ blastlab.html

Noriler, S. A., Savi, D. C., Aluizio, R., Palácio-Cortes, A. M., Possiede, Y. M., and Glienke, C. (2018). Bioprospecting and structure of fungal endophyte communities found in the Brazilian biomes, Pantanal, and Cerrado. Front. Microbiol. 9:1526. doi: 10.3389/fmicb.2018.01526

Novas, M. V., Iannone, L. J., Godeas, A. M., and Scervino, J. M. (2012). Evidence for leaf endophyte regulation of root symbionts: effect of Neotyphodium endophytes on the pre-infective state of mycorrhizal fungi. Symbiosis 55, 19-28. doi: 10 . 1007/s13199-011-0140-4

Ofek-Lalzar, M., Gur, Y., Ben-Moshe, S., Sharon, O., Kosman, E., Mochli, E., et al. (2016). Diversity of fungal endophytes in recent and ancient wheat ancestors Triticum dicoccoides and Aegilops sharonensis. FEMS Microbiol. Ecol. 92:fiw152. doi: 10.1093/femsec/fiw152

Oksanen, J., Blanchet, F. G., Friendly, M., Kindt, R., Legendre, P., McGlinn, D., et al. (2017). Vegan: Community Ecology Package. R package version 2.4-3. Available at: https://CRAN.R-project.org/package=vegan

Omacini, M., Eggers, T., Bonkowski, M., Gange, A. C., and Jones, T. H. (2006). Leaf endophytes affect mycorrhizal status and growth of co-infected and neighbouring plants. Funct. Ecol. 20, 226-232. doi: 10.1111/j.1365-2435.2006. 01099.x

Omacini, M., Semmartin, M., Pérez, L. I., and Gundel, P. E. (2012). Grassendophyte symbiosis: a neglected aboveground interaction with multiple belowground consequences. Appl. Soil Ecol. 61, 273-279. doi: 10.1016/j.apsoil. 2011.10.012

Ortuñez, E., and de la Fuente, V. (2010). Epidermal micromorphology of the genus Festuca L. (Poaceae) in the Iberian Peninsula. Plant. Syst. Evol. 284, 201-218. doi: 10.1007/s00606-009-0248-7

Peláez, F., Collado, J., Arenal, F., Basilio, A., Cabello, A., Díez Matas, M. T., et al. (1998). Endophytic fungi from plants living on gypsum soils as a source of secondary metabolites with antimicrobial activity. Mycol. Res. 102, 755-761.

Ponce, M. A., Bompadre, M. J., Scervino, J. M., Ocampo, J. A., Chaneton, E. J., and Godeas, A. M. (2009). Flavonoids, benzoic acids and cinnamic acids isolated from shoots and roots of Italian rye grass (Lolium multiflorum Lam.) with and without endophyte association and arbuscular mycorrhizal fungus. Biochem. Syst. Ecol. 37, 245-253. doi: 10.1016/j.bse.2009.03.010

Porras-Alfaro, A., Herrera, J., Sinsabaugh, R. L., Odenbach, K. J., Lowrey, T., and Natvig, D. O. (2008). Novel root fungal consortium associated with a dominant desert grass. Appl. Environ. Microbiol. 74, 2805-2813. doi: 10.1128/AEM. 02769-07

Redman, R. S., Kim, Y. O., Woodward, C. J., Greer, C., Espino, L., Doty, S. L., et al. (2011). Increased fitness of rice plants to abiotic stress via habitat adapted symbiosis: a strategy for mitigating impacts of climate change. PLoS One 6:e14823. doi: 0.1371/journal.pone.0014823

Ridout, M., Houbraken, J., and Newcome, G. (2017). Xerotolerance of Penicillium and Phialocephala fungi, dominant taxa of fine lateral roots of woody plants in the intermountain Pacific Northwest, USA. Rhizosphere 4, 94-103. doi: 10.1016/ j.rhisph.2017.09.004

Rodriguez, R., and Redman, R. (2008). More than 400 million years of evolution and some plants still can't make it on their own: plant stress tolerance via fungal symbiosis. J. Exp. Bot. 59, 1109-1114. doi: 10.1093/jxb/erm342 
Rodriguez, R. J., Henson, J., Van Volkenburgh, E., Hoy, M., Wright, L., Beckwith, F., et al. (2008). Stress tolerance in plants via habitat-adapted symbiosis. ISME J. 2, 404-416. doi: 10.1038/ismej.2007.106

Rojas, X., Guo, J., Leff, J., McNear, D., Fierer, N., and McCulley, R. (2016). Infection with a shoot-specific fungal endophyte (Epichloë) alters tall fescue soil microbial communities. Microb. Ecol. 72, 197-206. doi: 10.1007/s00248-0160750-8

Sabzalian, M., and Mirlohi, A. (2010). Neotyphodium endophytes trigger salt resistance in tall and meadow fescues. J. Plant Nutur. Soil Sci. 173, 952-957. doi: 10.1002/jpln.200900345

Sánchez Márquez, S., Bills, G. F., Acuña, L. D., and Zabalgogeazcoa, I. (2010). Endophytic mycobiota of leaves and roots of the grass Holcus lanatus. Fungal Divers. 41, 115-123.

Sánchez Márquez, S., Bills, G. F., Herrero, N., and Zabalgogeazcoa, I. (2012). Nonsystemic fungal endophytes of grasses. Fungal Ecol. 5, 289-297. doi: 10.1016/j. funeco.2010.12.001

Sánchez Márquez, S., Bills, G. F., and Zabalgogeazcoa, I. (2008). Diversity and structure of the fungal endophytic assemblages from two sympatric coastal grasses. Fungal Divers. 33, 87-100.

Santangelo, J. S., and Kotanen, P. M. (2016). Nonsystemic fungal endophytes increase survival but reduce tolerance to simulated herbivory in subarctic Festuca rubra. Ecosphere 7:e01260. doi: 10.1002/ecs2.1260

Santos, J. C., Finlay, R. D., and Tehler, A. (2006). Molecular analysis of arbuscular mycorrhizal fungi colonising a seminatural grassland along a fertilisation gradient. New Phytol. 172, 159-168. doi: 10.1111/j.1469-8137.2006.01799.x

Shade, A., and Handelsman, J. (2012). Beyond the Venn diagram: the hunt for a core microbiome. Environ. Microbiol. 14, 4-12. doi: 10.1111/j.1462-2920.2011. 02585.x

Sieber, T. H., and Grünig, C. R. (2013). "Fungal root endophytes," in The Hidden Half, eds A. Eshel and T. Beeckman. (Boca Raton: CRC Press). doi: 10.1201/ 9780203909423.ch49

Siless, G. E., Gallarfo, G. L., Rodriguez, M. J., Rincón, Y. A., Godeas, A. M., and Cabrera, G. M. (2018). Metabolites from the dark septate endophyte Drechslera sp. evaluation by LC/MS and principal component analysis of culture extracts with histone deacetylase inhibitors. Chem. Biodivers. 15:e1800133. doi: 10.1002/ cbdv.201800133

Slaughter, L., and McCulley, R. (2016). Aboveground Epichloë coenophiala-Grass associations do not affect belowground fungal symbionts or associated plant, soil parameters. Microb. Ecol. 72, 682-691. doi: 10.1007/s00248-016-0828-3

Song, M., Chai, Q., Li, X., Yao, X., Li, C., Christensen, M., et al. (2015). An asexual Epichloë endophyte modifies the nutrient stoichiometry of wild barley (Hordeum brevisubulatum) under salt stress. Plant Soil 387, 153-165. doi: 10. 1007/s11104-014-2289-0

Sunitha, V. H., Nirmala Devi, D., and Srinivas, C. (2013). Extracellular enzymatic activity of endophytic fungal strains isolated from medicinal plants. World J. Agric. Sci. 9, 1-9. doi: 10.5829/idosi.wjas.2013.9.1.72148

Vandegrift, R., Roy, B., Pfeifer-Meister, L., Johnson, B., and Bridgham, S. (2015). The herbaceous landlord: integrating the effects of symbiont consortia within a single host. Peer J. 3:e1379. doi: 10.7717/peerj.1379

Vázquez de Aldana, B. R., Bills, G., and Zabalgogeazcoa, I. (2013). Are endophytes an important link between airborne spores and allergen exposure? Fungal Divers. 60, 33-42. doi: 10.1007/s13225-013-0223-z

Vázquez de Aldana, B. R., Romo, M., Garcia-Ciudad, A., Petisco, C., and GarciaCriado, B. (2011). Infection with the fungal endophyte Epichloe festucae may alter the allelopathic potential of red fescue. Ann. Appl. Biol. 159, 281-290. doi: $10.1111 / \mathrm{j} .1744-7348.2011 .00495 . \mathrm{x}$

Wali, P. R., Ahlholm, J. U., Helander, M., and Saikkonen, K. (2007). Occurrence and genetic structure of the systemic grass endophyte Epichloe festucae in fine fescue populations. Microb. Ecol. 53, 20-29. doi: 10.1007/s00248-006-9076-2

Waller, F., Achatz, B., Baltruschat, H., Fodor, J., Becker, K., Fischer, M., et al. (2005). The endophytic fungus Piriformospora indica reprograms barley to salt-stress tolerance, disease resistance, and higher yield. Proc. Nat. Acad. Sci. U.S.A. 102, 13386-13391. doi: 10.1073/pnas.0504423102

White, T. J., Bruns, T., Lee, S., and Taylor, J. (1990). "Amplificacition and direct sequencing of fungal rigosomal RNA genes for phylogenetics," in PCR Protocols: A guide to Methods and Applications, ed M. A. Innis (San Diego, CA: Academic Press), 315-322.

Xie, Y., Han, S., Li, X., Amombo, E., and Fu, J. (2017). Amelioration of salt stress on bermudagrass by the fungus Aspergillus aculeatus. Mol. Plant-Microbe Interact. 30, 245-254. doi: 10.1094/MPMI-12-16-0263-R

Yang, B., Wang, X. M., Ma, H. Y., Yang, T., Jia, Y., Zhou, J., et al. (2015). Fungal endophyte Phomopsis liquidambari affects nitrogen transformation processes and related microorganisms in the rice rhizosphere. Front. Microbiol. 6:982. doi: $10.3389 /$ fmicb.2015.00982

Zabalgogeazcoa, I., Cuesta, M. J., Arellano, J. B., Mellado-Ortega, E., Oiz, L. F., Oiz, L., et al. (2018). "A Diaporthe endophyte improves the field performance of tritordeum," in Proceedings of the Book of Abstracts of the 10th International Symposium on Fungal Endophytes of Grasses, eds B. R. Vázquez de Aldana and I. Zabalgogeazcoa (Salamanca: Universidad de Salamanca), 121.

Zabalgogeazcoa, I., Gundel, P., Helander, M., and Saikkonen, K. (2013). Nonsystemic fungal endophytes in Festuca rubra plants infected by Epichloë festucae in subarctic habitats. Fungal Divers. 60, 25-32. doi: 10.1007/s13225-0130233-x

Zabalgogeazcoa, I., Romo, M., Keck, E., Vázquez de Aldana, B., García Ciudad, A., García Criado, B., et al. (2006). The infection of Festuca rubra subsp. pruinosa by Epichloë festucae. Grass Forage Sci. 61, 71-76. doi: 10.1111/j.1365-2494.2006. 00509.x

Zabalgogeazcoa, I., Vázquez de Aldana, B. R., García Criado, B., and García Ciudad, A. (1999). The infection of Festuca rubra by the fungal endophyte Epichloë festucae in Mediterranean permanent grasslands. Grass Forage Sci. 54, 91-95. doi: 10.1046/j.1365-2494.1999.00155.x

Zhong, R., Xia, C., Ju, Y., Li, N., Zhang, X., Nan, Z., et al. (2018). Effects of Epichloë gansuensis on root-associated fungal communities of Achnatherum inebrians under different growth conditions. Fungal Ecol. 31, 29-36. doi: 10. 1016/j.funeco.2017.10.005

Conflict of Interest Statement: The authors declare that the research was conducted in the absence of any commercial or financial relationships that could be construed as a potential conflict of interest.

Copyright $\odot 2019$ Pereira, Vázquez de Aldana, San Emeterio and Zabalgogeazcoa. This is an open-access article distributed under the terms of the Creative Commons Attribution License (CC BY). The use, distribution or reproduction in other forums is permitted, provided the original author(s) and the copyright owner(s) are credited and that the original publication in this journal is cited, in accordance with accepted academic practice. No use, distribution or reproduction is permitted which does not comply with these terms. 